\title{
Formação, saúde mental e trabalho: um patrimônio e uma estratégia
}

\author{
Wladimir Ferreira Souza, ${ }^{\text {Orcid, I, } \star \star ~ J u s s a r a ~ C r u z ~ d e ~ B r i t o, ~}{ }^{\text {Orcid, II Milton Raimundo Cidreira de Athayde Orcid, I }}$ \\ ${ }^{I}$ Universidade do Estado do Rio de Janeiro, Rio de Janeiro, RJ, Brasil \\ II Fundação Oswaldo Cruz, Rio de Janeiro, RJ, Brasil
}

\section{Resumo}

Este artigo propõe-se a tratar da formação no campo da Saúde do Trabalhador, com foco nas relações entre Saúde Mental e Trabalho, buscando colaborar para o desenvolvimento da orientação clínica do trabalho. Considera-se a pertinência de um processo de formação continuada que opere efetivamente de acordo com o patrimônio da Psicologia da Atividade de Trabalho e da démarche ergológica, envolvendo diferentes tipos de atores e organizações, a partir de questões que emergem das situações de trabalho. Apresenta-se uma estratégia empreendida, privilegiando as contribuições da abordagem Psicodinâmica do Trabalho (PdT), uma vez que se trata de uma referência incontornável para a análise das relações entre o trabalho, os processos de subjetivação e a saúde mental.

Palavras-chave: formação; saúde mental e trabalho; atividade; ergologia.

\section{Training, mental health and work: a patrimony and a strategy}

\begin{abstract}
This paper proposes to deal with training in the area of Worker's Health, focusing on the relationship between Mental Health and Work, seeking to collaborate in the development of the clinical orientation of work. It is considered the pertinence of a process of continuous training that operates effectively according to the patrimony of Psychology of Work Activity and the ergologic démarche, involving different types of actors and organizations, from issues that emerge from the work situations. We present an undertaken strategy, favoring the contributions of the approach Psychodynamics of Work (PdT), since it is an inexorably reference for the analysis of the relations among work, subjectivation processes and mental health.
\end{abstract}

Keywords: training; mental health and work; activity; ergology.

\section{Introdução}

Considerando o quadro alarmante que persevera no Brasil no que tange à saúde dos trabalhadores ${ }^{1}$ e sua segurança no trabalho, o esforço de prevenção de adoecimentos e promoção da saúde coloca em destaque tanto a questão da formação de profissionais que atuam neste campo, quanto as ações de formação que esses desenvolvem, e que são dirigidas à população. $\mathrm{O}$ presente artigo busca colaborar para a discussão da questão da formação no campo da Saúde do Trabalhador, com foco nas relações entre Saúde Mental e Trabalho (SM\&T). Inicia-se com um breve percurso histórico sobre a Formação Profissional. Depois, apresenta-se a questão principal e o campo de análise e intervenção em que esta se situa para, em seguida, empreender-se uma discussão teórico-metodológica com base no patrimônio da Psicologia da Atividade de Trabalho e da démarche ergológica (e abordagens clínicas do trabalho afins), afirmando-se sua relevância em um processo de formação continuada sobre o foco apontado. Nesse sentido, apresenta-se uma estratégia de formação que envolve diferentes tipos de atores (profissionais e estudantes) que vem sendo desenvolvida no âmbito da chamada "extensão universitária". O artigo busca colaborar para o desenvolvimento da orientação clínica do trabalho (que explora pistas para além

^Este artigo foi elaborado durante o pós-doutoramento do primeiro autor, con supervisão da segunda autora, no Programa de Pós-graduação em Saúde Pública da Escola Nacional de Saúde Pública da Fundação Oswaldo Cruz. O terceiro autor participou da experiência de Extensão e da elaboração do texto.

$\star \star$ Universidade do Estado do Rio de Janeiro, Departamento de Psicologia Socia e Institucional. Rua São Francisco Xavier, 524 - $10^{\circ}$ andar - Instituto de Psicologia - Maracanã, Rio de Janeiro, RJ - Brasil. CEP: Email: souzalandi@uol. com.br, jussara@ensp.fiocruz.br, athayde.milton@gmail.com.

Apesar da relevância das questões referentes às relações sociais de sexo, elas não foram exploradas no presente texto. da presença de indícios psicopatológicos) na proposição de ações de formação em SM\&T no campo da Saúde do Trabalhador, privilegiando-se as contribuições da abordagem Psicodinâmica do Trabalho (PdT).

\section{A formação profissional: breve percurso histórico}

A Formação Profissional tem sua própria história, sendo fortemente relacionada com o movimento sócio-econômico e político. Lacomblez (2001) explora o tema, inicialmente registrando que, conforme Polanyi (1983), um duplo movimento pode ser visto, a partir do final do século XIX, na história dos países industrializados, configurando "dois tipos de orientação na gestão dos interesses do Estado" (LACOMBLEZ, 2001, p. 544). Um, subordinado aos interesses do mercado capitalista, entendendo o trabalho estreitamente limitado, como "capital humano". O outro tem como meta limitar os efeitos do primeiro, promovendo os "interesses sociais vitais".

Em seguida, a autora mobiliza a Teoria da Regulação (BOYER, 1986) para compreender os ciclos de expansão e crise do desenvolvimento capitalista, em suas relações com diferentes paradigmas de Formação. Segundo a teoria citada, três formas de relação salarial teriam ocorrido até o final do século XX, revelando no local de trabalho três diferentes modos de regulação: o primeiro, de tipo concorrencial; o segundo, marcado pelo Taylorismo, reforçando a divisão técnica e social do trabalho; e em seguida, o modo de regulação Fordista, que buscava gerar forte elevação da produção e consumo de massa.

A crise deste terceiro modo de regulação marcou a segunda metade do século XX, engendrando-se outro modo de regulação ("pós-fordista", "neo-fordista"?), 
com forte investimento em inovações tecnológicas e organizacionais (um novo "sistema de máquinas"), mais "flexíveis". Tem-se então uma nova articulação entre Formação e atividades profissionais inovadas (exigidas pelas mudanças tecnológicas e organizacionais), exigentes de conhecimento e experiência, configurando-se um cenário que demandava formas de participação dos trabalhadores. Foi neste contexto que as contribuições da Análise Ergonômica do Trabalho (BÉGUIN, 1998) e da Psicologia da Cognição (SAVOYANT, 1996) foram sendo incorporadas e desenvolvidas, e em seguida (anos 1990) a Didática Profissional (PASTRÉ; MAYEN; VERGNAUD, 2006; PASTRÉ, 1997).

Por fim, para analisar os processos pelos quais vêm passando os diferentes modos de pensar e realizar a formação de adultos, Santos e Lacomblez (2001/2002) mobilizam a análise de Jobert (2000), na qual o autor faz uso de três metáforas. A primeira sinaliza o modo de pensar e realizar a formação que é ainda hegemônico - "saber como armazenamento". Nele, entende-se o formando como memória armazenada e o profissional de formação como fornecedor de dados, paradigma considerado desencarnado e a-histórico. A segunda metáfora - "saber como ação" - remete ao que se estabelece a partir da provocação gerada pela distinção entre "trabalho prescrito" e "trabalho real", estando seu foco na intervenção que visa à transformação do meio de trabalho, do profissional de formação se esperando que colabore para criar as condições que viabilizem o desenvolvimento de competência. De sua evolução emerge a terceira metáfora - "formação como desenvolvimento" - caracterizando um paradigma que não só busca mudanças nas situações de trabalho, como também a transformação dos protagonistas do trabalho (e dos profissionais de formação), tanto no sentido pessoal quanto profissional. Neste amplo e rico patrimônio, a experiência de formação encaminhada na extensão universitária que apresentaremos neste artigo situa-se, a nosso ver, no último paradigma.

O histórico desta processualidade encontra-se brilhantemente apresentado em livro coordenado por Teiger e Lacomblez (2013), para o qual remetemos os leitores. Nele tem destaque o paradigma (construído a partir dos anos 1960-70) que denominam "Formação dos atores na e pela análise do trabalho, pela e para a ação", visando ao compartilhamento de saberes e à construção conjunta de conhecimentos úteis às necessárias e desejadas mudanças no trabalho. A experiência de formação aqui apresentada o tem como horizonte referencial, implementando-se apenas o que foi possível no momento atual, neste contexto específico.

Quanto às relações entre saúde mental e trabalho, a discussão atual no Brasil - seja no campo mais geral da Saúde do Trabalhador - ST (ATHAYDE, M.; SOUZA, 2015; MINAYO-GOMEZ; MACHADO; PENA; 2011), seja quando a ênfase encontra-se nas relações entre os processos de trabalho e subjetividade / saúde mental - vem sendo objeto de interesse dos autores do presente texto, em suas diferentes inserções e experiências profissionais
(RAMMINGER; ATHAYDE, M.; BRITO, 2013; SOUZA, 2013; MASSON; BRITO; ATHAYDE, M., 2011; ATHAYDE, M., 2011; ATHAYDE, M.; BRITO, 2011).

No interior do campo da ST diferentes denominações vêm sendo dadas quando o foco está nas referidas relações. Alguns autores (SELIGMANN-SILVA, 2011; PAPARELLI; SATO; OLIVEIRA, 2011) a designam por "Saúde Mental Relacionada ao Trabalho", 2 outros, "Saúde Mental e Trabalho" (ATHAYDE, M., 2011; LIMA, 2013). Optamos, no artigo, pelo uso da expressão Saúde Mental e Trabalho (SM\&T).

\section{A questão principal e seus delineamentos}

Com base em nossas pesquisas (SUPRANI; ATHAYDE, V.; ATHAYDE, M., 2015; SOUZA, 2013; ATHAYDE, M., 2011; ATHAYDE, M. et al., 2010), consideramos que existem limites no espectro dos chamados "transtornos mentais e comportamentais relacionados ao trabalho", dado seu caráter redutor ao psicopatológico e à ênfase exclusiva no impacto ao qual o trabalhador passivamente sofreria. Assim, perguntamos: como contribuir para a formação no campo da ST avançando em direção a uma lógica de compreensão mais dinâmica das relações entre saúde (mental) e trabalho, aquela que não se limita à (necessária, mas não suficiente) detecção e denúncia dos "impactos" nocivos, geradores de um quadro em que passivamente os trabalhadores atingidos experimentariam transtornos mentais graves? Como contribuir para incorporar e desenvolver, no campo da ST, uma concepção mais psicodinâmica dessas relações? Partimos da premissa de que um passo importante poderia ser dado por meio de uma estratégia que visasse à construção e à consolidação de um processo de formação continuada que operasse efetivamente de acordo com o patrimônio da Psicologia da Atividade de Trabalho (LACOMBLEZ et al., 2016; TEIGER; LACOMBLEZ, 2013) e da démarche ergológica (SCHWARTZ; DURRIVE, 2010; SCHWARTZ, 2000; ATHAYDE, M.; SOUZA; BRITO, 2014), envolvendo diferentes tipos de atores e organismos, a partir das situações de trabalho e das questões que lhes são pertinentes (SILVA et al., 2009). Antes de apresentarmos a estratégia que elaboramos e implementamos, cabe destacar a perspectiva histórica, o patrimônio teórico e metodológico e alguns dos conceitos fundamentais que a balizam.

\section{Discussão teórico-metodológica: patrimônio, caixa de ferramentas e conceitos fundamentais}

De acordo com Athayde, M. e Souza (2015), a expressão "Saúde do Trabalhador" (ST) pode ser entendida como um conceito, mas também como um modelo de pensar-agir:

Designa, então, um campo de conhecimento e intervenção no âmbito das políticas públicas, envolvendo uma rede de relações entre diferentes posições em luta que se desenvolve no interior da saúde coletiva e que tem como objeto de estudo e intervenção as relações entre o trabalho e a saúde. Seu foco está nas mudanças nos processos de trabalho,

${ }^{2}$ Concordamos com Seligmann-Silva (2011) quando afirma que a unicidade corpo-mente torna saúde geral e mental indissociáveis. Esta é também a posição de Athayde, M. (2011). Dessa forma, em alguns trechos o termo "mental" aparecerá entre aspas ou entre parênteses para denotar essa indissociabilidade.

Fractal, Rev. Psicol., v. 30 - n. 2, p. 121-130, 2018 
contemplando as relações saúde-trabalho em toda sua complexidade, via atuação multiprofissinal, interdisciplinar e intersetorial (ATHAYDE, M.; SOUZA, 2015, p. 599).

Uma das conquistas neste campo foi que a execução das ações voltadas para a saúde dos trabalhadores tornou-se uma atribuição do Sistema Único de Saúde (SUS), com prescrição na Constituição Federal de 1988 (BRASIL, 1988/2008).

Tais lutas e vitórias consolidaram-se em leis e portarias. A Lei $n^{\circ} 8.080$ (BRASIL, 1990) regula, em todo o território nacional, as ações e serviços de saúde e, em consonância com o artigo 200 da Constituição Federal, inclui no campo de atuação do SUS a execução de ações de saúde do trabalhador. As Portarias no 2.728/2009 e $\mathrm{n}^{\mathrm{o}}$ 1.823/2012 (BRASIL, 2009, 2012) dispõem sobre a implantação dos Programas de Saúde do Trabalhador (PST), dos Centros de Referência em Saúde do Trabalhador (CEREST) nos estados e municípios, e da Rede Nacional de Atenção Integral à Saúde do Trabalhador (RENAST). Os CERESTs (dispositivos estratégicos para a consolidação da RENAST) podem ser de âmbito estadual, regional ou municipal. O CEREST com o qual mantemos interlocução é de abrangência regional, compreendendo quatro municípios.

Cabe a ele, entre outras atribuições, desempenhar as funções de suporte técnico, de educação permanente, de coordenação de projetos de promoção, vigilância e assistência à saúde dos trabalhadores, no âmbito de sua área de abrangência (BRASIL, 2012).

Contudo, no que se refere às relações entre saúde mental e trabalho encontram-se dificuldades específicas, tendo em vista que essa problemática geralmente não ganha efetiva visibilidade e reconhecimento (NEVES; BRITO; ATHAYDE, M., 2010). Já Souza, Rodrigues e Santos (2014) detectaram outro problema ao analisarem publicações do Conselho Federal de Psicologia (CREPOP/CFP, 2008; CFP, 2010). Nelas constata-se que a formação dos psicólogos (salvo exceções) não contempla de modo suficiente uma abordagem crítica que considere o vínculo entre os processos de trabalho e subjetivação, a gestão e formas de gerenciamento e a ocorrência de casos de sofrimento psíquico patogênico ou mesmo de adoecimento mental constatado. Assim, muitos profissionais negligenciam a presença desta problemática em suas práticas e, em muitos casos, a individualizam, pondo destaque na psicopatologia estrito senso, ou nos chamados "riscos psicossociais", neste caso em seu limitado referencial, como entendem Dejours (2012) e Clot (2010).

No campo social mais amplo pode-se verificar que a minimização e até mesmo a negligência em torno da importância do que está em foco apontam não só para a necessidade e premência de formação mais específica na graduação em Psicologia, como de socialização, explanação e discussão dessa temática com diversos atores sociais, para além do âmbito acadêmico, o que impõe a investigação acerca dos fatores que contribuem para que

Fractal, Rev. Psicol., v. 30 - n. 2, p. 121-130, 2018 uma visão reducionista da saúde e do trabalho persista e esteja presente em grande parte das análises e propostas de formação e/ou de pesquisa $\leftrightarrow$ intervenção.

Podemos tomar como exemplo o que traz Brito (2015), ao analisar um número significativo de monografias do Curso de Especialização em Saúde do Trabalhador e Ecologia Humana (Presencial e EAD) ministrado pela Escola Nacional de Saúde Pública (Fundação Oswaldo Cruz-RJ), apresentadas em 2012, 2013 e 2014. A autora buscou qualificar as 451 monografias analisadas no que tange a alguns de seus aspectos quantitativos e qualitativos. Entre outras constatações, seu estudo revelou que no conjunto das monografias que privilegiaram o olhar sobre Saúde Mental e Trabalho, os principais subtemas tratados foram: transtornos mentais; estresse e burnout; assédio moral. Enfim, a autora conclui:

Pode-se dizer que o conjunto dos trabalhos visou à notificação de casos e a comprovação de nexos causais. Merece registro o fato de que a categoria 'sofrimento' foi empregada de forma tangencial em poucos estudos. Na verdade, toda a complexa dinâmica trabalho-subjetividade não foi, em geral, considerada nessas monografias, diminuindo a capacidade de compreensão dos problemas vinculados (BRITO, 2015, p. 32, grifo da autora).

Entendemos que as constatações do estudo revelam o que ocorre em um quadro mais amplo em nosso país, no que tange à SM\&T. Muito frequentemente põe-se a ênfase na necessidade do estabelecimento do nexo causal dos chamados "transtornos mentais e comportamentais relacionados ao trabalho", conforme a denominação oficialmente reconhecida pelo Ministério da Saúde e pelo Ministério da Previdência Social do Brasil. Contudo, ao se privilegiar esse necessário eixo de análise, muitas vezes deixa-se de destacar outros aspectos do trabalho que não levam ao adoecimento mental e sim à produção de sentido, ao prazer, ao desenvolvimento individual e coletivo, conforme assinalam Clot (2011) e Souza (2013), por exemplo. Decerto tem contribuído para esse quadro a persistente negligência de que o trabalhar envolve uma intensa mobilização subjetiva. Conforme a abordagem Psicodinâmica do Trabalho (PdT), nesse processo vivencia-se um sofrimento psíquico (DEJOURS, 1988) que pode sim tornar-se patogênico, mas não necessariamente. Pode ele ser capaz de tomar outro rumo, em direção à criatividade e prazer, colaborando para a realização de si (DEJOURS, 2012), na perspectiva da saúde. Entende-se então que "o trabalhar" - enquanto atividade individual e coletiva - é fundamental para a vida dos humanos (é constitutivo da espécie e estruturante de seu psiquismo) e jamais é neutro em relação à saúde.

Para Théry (2006) algumas abordagens têm contribuído para que se imponha uma representação fatalista do sofrimento no trabalho. Contrário a essa representação, o autor reconhece que os sofrimentos patogênicos e as patologias estão presentes nas histórias dos sujeitos no trabalho, sem dúvida, mas destaca que é necessário passar da constatação ao combate; da análise ao engajamento; da solidão à ação coletiva; de uma vitimização estéril à dignida- 
de resgatada. Caso contrário, é grande o risco de confinar os sujeitos que trabalham a uma comunidade de vítimas passivas, ideia tão alienante quanto o sofrimento pode ser.

$\mathrm{Na}$ discussão aqui proposta, o conceito de sofrimento psíquico $^{3}$ reveste-se de grande importância. Dado não haver consenso em seu uso na comunidade científica, o debate sobre seu reconhecimento no trabalho é complexo, não ocorrendo sem dificuldades e controvérsias, conforme será exposto adiante.

De acordo com Guérin et al. (2001), a atividade de trabalho é o elemento central que organiza e estrutura os componentes da situação de trabalho, representando a maneira como aqueles que trabalham alcançam os objetivos que lhes foram designados. Isto é, representa a maneira como os resultados do trabalho são obtidos e os meios utilizados.

No entanto, os autores - referências da Ergonomia da Atividade - destacam que existem, de fato, pontos de vista diferentes sobre as situações de trabalho em toda organização, e estes precisam ser contrastados. Da confrontação entre o ponto de vista da atividade e outros pontos de vista (como o dos resultados, o da comercialização, das condições de produção, e mesmo o sindical) resultará a evolução das situações de trabalho. O ponto de vista da atividade de trabalho não se traduz de forma estruturada nas organizações, ${ }^{4}$ embora seja a compreensão da atividade que permite a transformação do trabalho, no entender dos autores. Portanto, uma leitura crítica do funcionamento da organização tem como ponto de partida a maneira pela qual os operadores efetivamente realizam o trabalho que lhes foi prescrito.

Do ponto de vista epistemológico, Schwartz (2004, p. 142) propõe-se a investigar "em que medida a ergonomia seja hoje, talvez, uma propedêutica à epistemologia". E em seguida (SCHWARTZ, 2004, p. 144), colocando em prática sua proposta de análise sinérgica entre saberes, entre disciplinas e mesmo entre abordagens em seu interior, afirma que “o conceito de 'sofrimento no trabalho' é uma verdadeira conquista [...] graças aos avanços da psicodinâmica do trabalho". Conforme esta démarche ergológica, Brito e Athayde, M. (2003) afirmam ser preciso ir adiante em relação àquela descoberta da Ergonomia da Atividade, ampliando o conceito de atividade de trabalho, distinguindo realidade e real do trabalho (DEJOURS, 2012), ou atividade realizada e real da atividade (CLOT, 2010).

Conforme Athayde, M. (2011), é consensual que, na formação social brasileira, pululam as possibilidades e casos concretos de adoecimento e acidentes de trabalho, sendo absolutamente necessário denunciar tal nocividade. Não obstante, o perigo certamente persistirá, a seu ver, caso não se compreenda que a denúncia é sim uma ação necessária, mas não suficiente. A crítica pura e simples tem se revelado parcial e redutora, contendo o risco de

${ }^{3}$ Registramos a não existência de consenso no uso deste vocábulo na comunidade científica. Alguns autores até mesmo o têm usado como uma noção do senso comum. Do ponto de vista conceitual, acompanhamos o sentido que tem dado Dejours $(1988,2004,2012)$ em sua obra, no interior da abordagem Psicodinâmica do Trabalho, como capacidade de ser afetado pelas experiências vividas.

${ }^{4}$ Com frequência ele está ausente, negado ou subordinado, mesmo pelo ponto de vista sindical. Ele tem que ser construído/constituído, para o que uma intervenção do psicólogo pode muito contribuir. basear-se em um referencial que simplifica a questão, tornando-se um fardo que age na prática como obstáculo epistemológico na busca de melhor compreender $\leftrightarrow$ transformar. Enfim, reitera a nobreza da experiência-trabalho, pois foi através dela que se constituiu a espécie humana e estruturou-se/estrutura-se/desestrutura-se a vida psíquica.

Nesse sentido, o referido autor vem propondo uma ampla e necessária discussão, focando seu texto na interrogação sobre o 'mental' presente no trabalhar, buscando também fazer considerações sobre a incorporação dos protagonistas do trabalho em análise no processo de pesquisa $\leftrightarrow$ intervenção, por entender que persistem resistências a essa participação efetiva. Reiteramos aqui a relevância de uma "coanálise", conforme a démarche ergológica (com o Dispositivo Dinâmico de Três Polos - DD3P e os Encontros sobre o Trabalho), na linhagem da Ergonomia da Atividade (formas de confrontação) e do Modelo Operário Italiano de produção de conhecimento e luta pela saúde MOI, explorada pela PdT e pela Clínica da Atividade.

Em nosso entendimento, especialmente a abordagem Psicodinâmica do Trabalho (PdT) tem se apresentado como uma referência incontornável no que tange à análise das relações entre o trabalho, os processos de subjetivação e a saúde mental. Dejours (2004, p. 27) afirma que trabalhar é preencher a lacuna entre o prescrito e o que será objetivamente realizado, dando então relevo ao que conceitua por "real do trabalho", considerando que este "sempre se manifesta afetivamente para o sujeito, aí se estabelece uma relação primordial de sofrimento, experimentada pelo sujeito, corporificada".

O fato de o trabalho (como a vida) gerar uma experiência ("pática"), sempre singular - que conceitua usando o vocábulo sofrimento psíquico -, poder tomar um rumo seja patogênico ou criativo/prazeroso/estruturante, depende de uma (psico)dinâmica complexa, cujo resultado jamais é dado de antemão. Nesse sentido, o referido conceito busca dar conta da relação, do fenômeno de proteção da subjetividade com relação ao mundo, na busca de meios para sobre ele agir, visando a encontrar o melhor destino para o sofrimento vivido e a superação da resistência do real. Enfim, para Dejours (2004), o sofrimento - que antecede o trabalho na experiência humana, pois ele é primeiro, "não é o trabalho que causa sofrimento" (MOLINIER, 2013, p. 80) - está na origem da inteligência no trabalho, inteligência esta que parte em busca do mundo para se colocar à prova.

O sofrimento psíquico no trabalho vai se manifestar em um indivíduo/sujeito singular corporificado, mais precisamente no que Dejours $(1991,2004)$ chama de "segundo corpo" (para além do biológico), o corpo (subjetivo) que cada um de nós habita, que se experimenta afetivamente, que está engajado na relação com o outro.

Não obstante todo o referencial epistemológico e teórico-metodológico-técnico disponível, parcialmente aqui explorado, são grandes e diversos os desafios e as fragilidades persistentes. Entende-se que uma estratégia de Formação continuada de profissionais de saúde e de 
futuros profissionais de Psicologia para cuidar de quem trabalha (como no caso explorado no referido projeto de extensão universitária), deve necessariamente incluir informações e gerar conhecimento para "cuidar do trabalho" (ATHAYDE, M.; SOUZA, 2015), na linha de uma Clínica do Trabalho (CLOT; LHUILIER, 2010), não se restringindo a um trabalhador específico. De forma que o sofrimento no trabalho, compreendido em sua esfera relacional, não tome o rumo patogênico, adoecedor. Deve-se desafiar a lógica perversa que conduz o trabalho a se tornar e/ou ser visto inexoravelmente como um fator desestruturante (para alguns, ao menos até que se elimine o capitalismo...) e não um fator de equilíbrio, ou um “operador de saúde” (CLOT, 2011).

Vamos agora apresentar o processo formativo que, enquanto extensão universitária, vem tendo a participação de diversos tipos de atores e organizações - não apenas os profissionais de saúde ligados à abrangência do referido CEREST. Com foco nas relações entre saúde (mental) e trabalho, ele é inspirado no patrimônio que envolve a Psicologia da Atividade de Trabalho e outras abordagens disciplinares - como a Ergonomia da Atividade, que alimenta essa Psicologia - e que tem também conformidade com a estratégia proposta pela Ergologia, na linha do que Durrive (2010a) denomina "ergoformação".

\section{Contribuições da Ergologia para a Formação em Saúde do Trabalhador: a "Ergoformação"}

Vimos experimentando em nossas pesquisas $\leftrightarrow$ intervenções um encaminhamento epistêmico e metodológico que tem o ponto de vista da atividade como operador transversal (BRITO, 2011), incorporando diferentes influências de métodos e técnicas de algumas outras ciências que têm o trabalho como objeto.

Souza e Christo (2015) assinalam que foi a partir das experimentações do Modelo Operário Italiano de luta pela saúde e produção de conhecimento (MOI) - onde se verifica a proposição de um dispositivo de coprodução de conhecimento sobre o trabalho envolvendo os protagonistas da atividade e os profissionais dos conceitos que Schwartz (2004) propôs, a partir da década de 1990, um regime de produção de saberes e transformações que denominou "dispositivo dinâmico de três polos" (DD3P), como uma consequência direta da ideia de renormatização na atividade, cujo fundamento encontrou na filosofia da vida de Canguilhem (2000). O DD3P foi proposto buscando superar limites e contradições presentes no que se denominou "Comunidade Científica Ampliada" no MOI.

Considerando que o ponto de vista da atividade e o DD3P nos permitem refletir sobre as atividades (quaisquer que sejam, em quaisquer circunstâncias que se queira produzir ou difundir saberes sobre a atividade humana), temos caminhado no sentido da construção de um dispositivo de formação continuada, visando à criação de meios para, através do diálogo intersaberes, produzir conhecimento e promover/produzir saúde (mental), na perspectiva do compreender $\leftrightarrow$ transformar o trabalho. A estratégia empregada tem forte afinidade com o "Programa de Formação em Saúde, Gênero e Trabalho nas Escolas" (BRI-
TO; ATHAYDE, M.; NEVES, 2003a, 2003b; NEVES; BRITO; ATHAYDE, M., 2010), outra configuração do DD3P já encaminhada no Brasil. Uma linhagem que tem os princípios presentes no paradigma rastreado por Teiger e Lacomblez (2013): (a) a formação é vista como um processo de construção de conhecimentos que pode assumir formas diversas, à diferença de uma simples transferência de conhecimentos de especialistas a leigos (não-especialistas); (b) a formação é entendida enquanto processo coletivo e recíproco ("formando, formamo-nos"); (c) ao empreender a análise crítica do trabalho cria-se a possibilidade de um outro olhar sobre o trabalho, percebendo aspectos desconhecidos e concebendo transformações potenciais; (d) os conhecimentos a construir em comum são de ordem teórica, metodológica e estratégica, eles provêm de fontes diversas e são mediatizados pela experiência de cada um, sendo colocados à prova da ação e são objetos de um processo progressivo de formalização; (e) a formação para a análise do trabalho deve possibilitar desenvolver os "saberes-fazer de prudência" e a capacidade de diagnóstico dos elementos nocivos a transformar no trabalho e em seu ambiente; (f) as intervenções conduzidas em meio de trabalho, segundo esses princípios, se inscrevem no campo das démarches indutivas e participativas articulando formação, pesquisa, ação.

Nesse caminhar fazemos nossa a indagação de Durrive (2002): o que muda ao conduzirmos um processo de formação em função de uma perspectiva ergológica? No entendimento do autor:

No fundo, um dispositivo com três polos é uma configuração que pode emergir de maneira muito diversa, desde que o encontro entre os saberes, aqueles saídos da experiência e aqueles que são mais formalizados, opere-se num espírito de respeito e de escuta recíproca, bem como com método. $\mathrm{O}$ método, segundo meu ponto de vista, consiste em 'problematizar o mundo', do mais 'micro' ao mais 'macro' da vida social (DURRIVE, 2002, p. 27-28).

\section{Traços de uma estratégia de formação: pistas e desafios}

Gomes (2014, p. 5) ressalta o necessário diálogo sobre os sentidos e os desafios que perpassam a chamada “extensão universitária", e aponta um caminho a seguir: "a intensificação da interação dialógica entre saberes e do papel formativo-pedagógico da extensão para os sujeitos envolvidos no processo extensionista". Destaca que a tendência apontada no Plano Nacional de Educação.

é que a extensão constitua-se como componente curricular obrigatório para todos os discentes o que por sua vez, dialoga com a concepção de que a extensão é essencial para uma formação consistente e referenciada socialmente pela interação dialógica envolvida no processo (GOMES, 2014, p. 5).

Este artigo tem como base empírica um Projeto de Extensão (que compõe o tripé com o ensino e a pesquisa) que vem sendo desenvolvido desde 2014, abordando as relações entre trabalho, gestão e saúde mental, na parceria entre uma Universidade pública e um Centro de Referência em Saúde do Trabalhador (CEREST) do estado do Rio de Janeiro. 
A interlocução com o CEREST se deu inicialmente com a direção da Unidade e, posteriormente, em reuniões com o Conselho Gestor do CEREST, formado por profissionais de saúde e "usuários" (membros do Controle Social) do SUS dos quatro municípios da área de abrangência do CEREST, coordenações dos PSTs municipais e a direção do CEREST. Teve a mediação de um dos autores, dado que além de docente universitário (coordenador do Projeto de Extensão citado) é também psicólogo do Centro de Referência mencionado.

A partir de convocações mútuas (os saberes da prática convocando os saberes científicos e vice-versa) deu-se início ao diálogo que resultou na parceria com o referido CEREST. Já, em certa medida, constituía-se naquele momento um dos elementos da estratégia de formação proposta no Projeto, o que colaborou para o início de um processo formativo envolvendo a construção compartilhada de conhecimentos - úteis a transformações - acerca das relações entre SM\&T, ampliando-se o número e as inserções profissionais dos trabalhadores interessados.

Nos diálogos estabelecidos com estes identificou-se um problema: por um lado, havia demanda crescente de informação, formação e ação em torno da temática "saúde mental e trabalho"; não obstante, na maioria das vezes que uma solicitação desse tipo era encaminhada a diferentes profissionais ou organismos especializados, ou a demanda ou a oferta (ou ambas) era formulada na lógica clássica da Pedagogia de viés comportamental e da Administração de Recursos Humanos, remetendo ao que tem sido denominado "treinamento" (ou "capacitação") sobre saúde mental, assim referenciada: "assédio moral"; "estresse laboral", "transtornos mentais e comportamentais relacionados ao trabalho"; "qualidade de vida no trabalho". Tendo seu viés um cunho mais assistencial do que de formação (formação pela e para a ação) e de efetiva prevenção e "promoção da saúde a partir das situações de trabalho" (SILVA et al., 2009).

A estratégia definida tem como base o entendimento de que a abordagem das relações entre saúde (mental) e trabalho não deve se restringir às questões como antes nomeadas, tampouco deve ser operada segundo a lógica de transmissão de informação dos especialistas aos potenciais atingidos, "conscientizando-os" dos problemas e dos melhores encaminhamentos previamente estabelecidos.

Assim, optamos - segundo o patrimônio já indicado - por uma estratégia de formação dinâmica e interativa, considerando haver uma via de mão dupla, pois que os coordenadores do processo encontram-se também como "aprendentes" (FREIRE, 2000). Conforme a démarche ergológica buscou-se imprimir uma dupla confrontação entre os saberes, em sua mútua ignorância e sapiência, via de regra gerando desconforto intelectual, demandando o exercício de humildade epistemológica (SCHWARTZ, 2002). Por outro lado, segundo a mesma perspectiva, os profissionais de saúde da rede também auferem ganhos na interlocução com outros trabalhadores não especialistas.
Tratando-se de uma estratégia de Formação que respeite a vida e a atividade humana, os eventos programados tendem a fortalecer seu caráter sempre singular. Em alguma medida os eventos apresentam um ineditismo, haja vista que a forma como ocorrem jamais pode ser plenamente prevista, definida de antemão, conhecida antecipadamente. Enfim, considerando as características da Extensão Universitária, buscamos também contemplar na mesma dinâmica do processo os futuros profissionais de Psicologia atuantes como "estagiários". Além de contemplar, simultaneamente, profissionais de saúde, trabalhadores com diferentes inserções nos mundos do trabalho e os "estagiários", também participam profissionais em função de gerenciamento e representantes do Controle Social (membros da sociedade civil - sindicatos, associações, organizações não governamentais e outras - que integram os conselhos gestores de políticas públicas. Nesse caso, são os representantes dos Conselhos Municipais de Saúde e do conselho gestor do CEREST). Esse formato contribui para afirmar um princípio de nosso patrimônio epistemológico: as questões que envolvem trabalho e saúde (mental) podem e devem ser encaminhadas em conjunto, dentro do possível. Ao envolver uma rede de atores, a estratégia auxilia na visibilização e compreensão dos problemas e possibilita uma visão mais dinâmica das relações entre saúde mental e trabalho.

Previamente à execução das diferentes modalidades de formação pertinentes com a estratégia procedeu-se à análise da demanda e da sua pertinência, envolvendo parte dos atores citados, com vista à "validação consensual" para sua realização. Entendemos que assim demos mais um passo na ampliação do debate - e da "comunidade ampliada de pesquisa $\leftrightarrow$ intervenção" - CAP-I (ATHAYDE, M.; SOUZA; BRITO, 2014).

Enfim, tal tipo de encaminhamento, na medida em que orientado pela Ergologia (DURRIVE, 2010b), exige a conquista das condições propícias à sinergia entre os dois primeiros polos do DD3P, o que se configura na construção de um terceiro polo (ético-epistêmico), exigindo uma espécie de disciplina intelectual, uma preocupação permanente:

A primeira exigência intelectual é a humildade diante dessa complexidade, para evitar que os saberes ocultos sejam eclipsados na atividade pelos saberes instituídos, os do ofício por exemplo. Em seguida - e é quase uma recíproca - deve-se adotar uma postura de exigência intelectual, de rigor, para socialmente dar corpo aos saberes ocultos da atividade (DURRIVE, 2010b, p. 311, grifo do autor).

Com tal orientação, desde 2014 vem sendo implementada uma série de modalidades de formação, como Oficinas, Cursos, Eventos, Encontros e Conversas sobre o Trabalho, assim como Ciclos de Debate. Os temas foram propostos após debates e deliberações com o Conselho Gestor do CEREST. Para garantir a divulgação desse conjunto de ações de formação, são enviadas mensagens por correio eletrônico (e-mail) e ofícios aos PSTs e outros setores pertinentes das Secretarias Municipais de Saúde; como também são feitos anúncios verbais em eventos e reuniões; e publicadas notícias no sítio Renast On-Line na Internet. 
Um dos primeiros desafios com que lidamos foi reunir as condições propícias e os atores interessados para que houvesse desde o início um encontro de caráter dialógico (BAKHTIN, 2008; FREIRE, 2000). A tática inicialmente empregada foi propor uma Oficina ("Dialogando sobre as relações entre Saúde Mental e Trabalho") que reunisse atores de diferentes inserções - profissionais de saúde, profissionais em função de gerência (ditos "gestores") e "usuários" (representantes do Controle Social) - no SUS dos quatro municípios abrangidos pelo referido CEREST. Buscou-se empregar ferramentas mais coerentes com a proposta eleita (tanto na linguagem dos textos, nas formas de apresentação e dinâmicas grupais), melhor mobilizando a todos na construção do conhecimento compartilhado.

$\mathrm{Na}$ linha dialógica proposta, entendemos que o vivente humano é produtor de textos, tendo o linguagear nobreza para esse vivente, emergindo em destaque a produção de sentido. A atribuição de sentido a um objeto (a uma palavra, a uma informação) não se reduz a uma operação de etiquetagem, sendo o produto de uma relação que cada indivíduo (locutor/interlocutor), a seu modo, constitui.

Neste artigo, em razão do limite de páginas, vamos explorar mais extensamente os achados referentes à atividade mais recentemente realizada, sobretudo pela rica produção de textos que nela ocorreu e por sua importância para a análise da estratégia como um todo. Considerando o processo, entendemos que se tratava do momento oportuno para propor a modalidade de DD3P denominado "Encontro sobre o Trabalho", envolvendo a análise coletiva sobre o processo de formação, buscando identificar lacunas, retomar conceitos e temas apresentados em atividades anteriores, fazer o levantamento de questões, dificuldades e temas de interesse dos participantes, a tratar naquele evento e em ações futuras. Com esse propósito, realizou-se um Ciclo de Debates denominado "Saúde Mental no Trabalho: o que nós temos a ver com isso?" Este evento destinou-se a profissionais de saúde, "usuários" (membros do Controle Social) e os chamados "gestores" do SUS atuantes nos municípios abrangidos pelo CEREST, e seus respectivos Programas de Saúde do Trabalhador, além de profissionais de outras organizações afins. Cabe ressaltar que desde o título propúnhamos uma convocação para o debate e o compartilhamento de conhecimentos e, ao mesmo tempo, uma provocação, incitamento à reflexão sobre as implicações que cada um tem com a questão da saúde (mental) no trabalho, a sua e a daqueles com quem convive, seja no trabalho, seja em outros ambientes. Buscou-se inicialmente retomar e fortalecer a compreensão sobre alguns temas e conceitos já tratados em atividades anteriores do Projeto, das quais alguns dos inscritos já haviam participado. Buscou-se também favorecer o relato de experiências e promover a produção de conhecimentos por intermédio de um debate sinérgico entre os saberes acadêmicos e os saberes da prática.

O evento ocorreu em duas manhãs, com intervalo de cerca de 40 dias entre o primeiro e o segundo Encontro. Vinte pessoas participaram do primeiro Encontro e onze do segundo (sete das quais estiveram no primeiro). A maioria eram profissionais da Saúde, mas comparecerem também profissionais de outras áreas, como Educação e Comércio. Além destes participaram todos os docentes e discentes, membros da equipe do Projeto. Não havia obrigatoriedade de ter participado do primeiro Encontro para realizar o estudo de campo proposto e comparecer ao segundo Encontro, pois as orientações sobre o método e procedimentos foram enviadas por e-mail para todos os possíveis interessados.

No primeiro, iniciou-se com uma curta exposição da Coordenação sobre a temática, explorando em especial o conceito de sofrimento psíquico. Também fez-se a crítica à vitimização do trabalhador, vista como tendência à redução do sujeito trabalhador a vítima passiva do processo produtivo.

A apresentação foi seguida por conversas sobre o assunto em pequenos grupos (acompanhadas por estagiárias que tinham como tarefa manter o foco da discussão, observar e registrar), concluindo-se com a apresentação para todos do que fora discutido, junto com comentários da Coordenação.

Sobre o que entendem por sofrimento, percebemos que alguns participantes revelavam uma recusa inicial para admitir que o conceito de sofrimento poderia ter um sentido para além do patogênico. Mas já nas conversas que se seguiram, uma das falas registrou que o sofrimento emerge quando não conseguem realizar "seu" trabalho de forma digna. Ou seja, não seria nocivo o trabalho em si, mas a falta de condição para seu exercício, gerando um quadro em que o trabalhador "tem que se anular", "frustrando-se". Outros comentaram o quanto "fatores externos", como a violência urbana, influenciam na geração de sofrimento.

Quanto às críticas por nós efetuadas à vitimização, alguns insistiram que os trabalhadores seriam sim vítimas dos processos produtivos, no que concerne às relações entre saúde mental e trabalho. Dada a forte assimetria das relações existentes, estariam efetivamente impossibilitados de modificar as condições de vida, trabalho e saúde e as situações que levam ao sofrimento psíquico patogênico no trabalho.

Entendendo que viver e trabalhar trazem consigo a experiência de sofrimento, o desafio estaria em saber entender tal sofrimento e conseguir trabalhar da melhor maneira possível.

Quanto às estratégias para não sucumbir, o debate abordou a não separação do trabalho em relação à vida, assinalando-se a importância de diversas estratégias para conseguir relaxar no extra-trabalho (em especial o vínculo com a família). O que se revelava muito difícil, dada a instabilidade no emprego, as condições degradadas de trabalho e o grande atraso dos salários no caso dos servidores públicos no período em que os Encontros foram realizados.

Quanto à dinâmica das conversas, mesmo no pequeno grupo em que houve ciclicamente dispersão, uma forte atenção era retomada quando algum ponto da conversa assumia para eles maior relevância. 
Na sequência do debate, identificamos que circulava na conversa a presença de uma lógica causal simples (se $a$, então $b$ ), binária, um dualismo que não contempla a dinâmica presente nessas situações, anulando o potencial crítico e transformador daquele que trabalha e de sua força enquanto classe social em luta.

Ao final, foi proposto que, para ser apresentado no Encontro seguinte, os participantes deveriam realizar o seguinte exercício: a partir da reflexão sobre o conceito de "sofrimento psíquico" apresentado no primeiro Encontro (quando sinalizamos não haver um consenso a respeito e expusemos como o entendemos), solicitamos que colocassem em análise o que ocorria em seu próprio ambiente de trabalho, se possível conversando com os colegas de trabalho a respeito.

No segundo Encontro os participantes apresentaram seus exercícios (feitos individualmente ou em duplas), entrecortados por comentários da Coordenação (buscando aprofundar o conteúdo dos relatos). A primeira exposição, extensa e muito rica, foi feita por um professor da rede municipal de ensino. Explorou sua experiência como professor e militante sindical, fazendo uma análise geral do que entende como sendo os elementos perturbadores da saúde do professor e como eles influenciam até mesmo na aparência e em seu cuidado pessoal. Sinalizou também a falta de espaço para o diálogo entre os professores e demais funcionários (tema que persistiu nas conversações ao longo do Encontro). Por fim, apontou para a banalização do adoecimento por parte de todos, exemplificando com a ideologia do "preciso trabalhar". Concluiu essa parte informando uma novidade: diz existirem "pontos de encontro" com professores para troca de experiências, do qual participa, o que considera útil na redução dos danos na saúde dos profissionais.

Passando aos relatos dos estudos de campo de outros participantes, uma profissional de saúde, percebendo a demanda por um espaço de escuta (privilegiando-o em relação à fala), assim como a ignorância dos trabalhadores em relação ao trabalho dos colegas, afirmou ter ficado "perplexa", ao detectar em uma conversa com duas pediatras do setor em que trabalha, o quanto cada profissional desconhece o trabalho da outra. Buscando ser propositiva a partir de sua perplexidade, ousou propor à chefia imediata que implantasse uma reunião mensal para esse tipo de diálogo.

Outra profissional de saúde, atuante na ST, primeiro leu um texto que encontrara na internet e em seguida privilegiou o "trocar forças, palavras e sentidos", o ver a si próprio para poder ver o outro.

Aproveitando uma frase do texto que a participante anterior lera ("para qualquer lugar que você queira ir sempre haverá um caminho"), outra trabalhadora, que assim como a anterior, também atua na ST, chamou atenção de que em sua vida aprendera que existe sempre alguma saída frente aos imprevistos. Expôs, a seu modo, o que Clot (1997) conceitua por catacrese, dando como exemplo sua descoberta de um modo diferente de instalação de um botijão caseiro de gás, improvisando com uma ferramenta da sua máquina de lavar roupa. Em seguida reiterou o que foi muito frequente no Encontro: evitar o isolamento e passarem a se reunir, em uma rede de apoio, buscando então melhor configuração de seu trabalho, como forma de adoecer menos.

Outra trabalhadora, também atuante na ST, considerando estarem os servidores com vários meses de atraso nos salários, mobilizou o que a PdT conceitua como psicodinâmica do reconhecimento, chamando atenção de que para alguns colegas seria estranha sua participação na Formação, na atual situação de precarização em que se encontravam. Contudo, ela afirmou que considerava esse tipo de atividade importante e prazerosa, pois eram situações como aquela que faziam valer a pena o seu trabalho. Ela relatou também, que em certo momento, devido ao "estresse" por que passava, teve momentos muito explosivos. Entretanto, a partir de alguns encontros e conversas que teve com colegas de profissão em situações aparentemente informais (durante o almoço, por exemplo) o quadro amenizou. Dando relevo ao que foi trazido por essa trabalhadora, a Coordenação apresentou uma questão, buscando explorar um dos enigmas do trabalho apontados pela PdT: o que os trabalhadores (em sua maioria) fazem para lidar com os desafios e adversidades do trabalho, conseguindo manter o "equilíbrio" e permanecer no campo da "normalidade"? Essa indagação adquiriu relevância na sequência do Encontro possibilitando chegar ao que entendemos como o seu principal resultado: a obtenção de um relativo consenso acerca da importância e da necessidade de espaços e Encontros para discussões e deliberações sobre o trabalho, para conhecer a atividade (sua e do outro) e poder contribuir para a construção de um trabalho saudável, prazeroso e emancipador, o que era inimaginável para alguns até então.

\section{Considerações finais}

Discutiu-se neste artigo o patrimônio teórico-metodológico que fundamentou a elaboração de uma proposta de Formação continuada que envolveu uma rede de atores, buscando contribuir para dar maior visibilidade e ampliar a compreensão dos problemas e possibilitar uma visão mais dinâmica das relações entre saúde mental e trabalho.

Ao apresentarmos a estratégia implementada apontamos as principais pistas e desafios detectados. Confirmamos a relevância da formação (pela e para a ação) em Saúde Mental e Trabalho no campo da Saúde do Trabalhador e a importância desta ocorrer por intermédio da constituição de espaços públicos de debates sinérgicos e de deliberações, de busca ativa de soluções com vistas à transformação, e não somente espaços e ocasiões para "treinamentos/capacitações" ou "troca de experiências".

Entendemos que é no interior do próprio curso do real que estão contidas as possibilidades de engendrar alternativas afirmadoras da vida, especialmente no campo da relação saúde (mental) e trabalho. Neste caso o conceito de sofrimento operaria, a nosso ver, como ferramenta de detecção de vivências "sentinela" do seu possível destino patogênico. Assim como a capacidade coletiva de engen- 
drar defesas coletivas de tipo estratégico alimentariam as possibilidades de promoção de saúde a partir das situações de trabalho.

Um dos desafios e pistas a desenvolver está no melhor modo de lidar com a atividade linguageira (e suas zonas de penumbra) em cada modalidade da Formação. $\mathrm{O}$ que percebemos requerer um manejo cuidadoso, sendo necessária a elaboração de métodos e técnicas ainda a serem desenvolvidos, agregando-se a colaboração de outros interlocutores. Tal enquadre deverá contribuir futuramente para tornar ainda mais propícias as condições para o exercício da Formação.

Por fim, sabe-se que a sinergia entre profissionais da ciência e trabalhadores da área de ST contribui para uma espiral ascendente de aprendizagem e desenvolvimento. $\mathrm{Na}$ estratégia que vimos desenvolvendo e que no artigo é o foco da análise, agregamos aos participantes outros trabalhadores, não especialistas no campo da ST. Verificamos que a sinergia de saberes toma uma nova riqueza, configurando-se a formação para todos os envolvidos, com força agregadora de descobertas mútuas.

\section{Referências}

ATHAYDE, M. Saúde 'mental' e trabalho: questões para discussão no campo da Saúde do Trabalhador. In: MINAYOGOMES, C.; MACHADO, J. M. H.; PENA, P. G. L. (Org.). Saúde do trabalhador na sociedade brasileira contemporânea. Rio de Janeiro: Fiocruz, 2011. p. 345-367.

ATHAYDE, M.; BRITO, J. Ergologia e Clínica do Trabalho. In: BENDASSOLli, P.; SOBOLL, L. A. (Org.). Clínicas do Trabalho. São Paulo: Atlas, 2011. p. 258-281.

ATHAYDE, M.; SOUZA, P. C. Z.; BRITO, J. Intervenção e pesquisa em Psicologia: uma postura ergológica. In: BENDASSOLLI, P.; SOBOLL, L. A. (Org.). Métodos de Pesquisa e Intervenção em Psicologia do Trabalho: Clínicas do Trabalho. São Paulo: Atlas, 2014. p. 129-158.

ATHAYDE, M.; SOUZA, W. F. Saúde do Trabalhador. In: BENDASSOLLI, P. F.; BORGES-ANDRADE, J. E. (Org.). Dicionário de Psicologia do Trabalho e das Organizações. São Paulo: Casa do Psicólogo, 2015. p. 597-605.

ATHAYDE, M. et al. A perspectiva da Ergologia e o campo da Saúde Mental e Trabalho. In: GLINA, D.; ROCHA, L. (Org.). Saúde Mental no Trabalho: da teoria à prática. São Paulo: Roca, 2010, p. 229-247.

BAKHTIN, M. Problemas da poética de Dostoiévski. 4. ed. Rio de Janeiro: Forense Universitária, 2008.

BÉGUIN, P. Stratégies de formation et de développement de l'ergonomie en entreprise: vers des modalités specifiques de intervention. Performances Humaines et Thecniques, $\mathrm{n}$. especial: Analyse ergonomique du travail et changements dans les situations de travail, p. 69-72, 1998.

BOYER, R. (Dir.). La théorie de la regulation: une analyse critique. Paris: La Découverte, 1986.

BRASIL. Constituição (1988). Constituição da República Federativa do Brasil: atualizada até a Emenda Constitucional ${ }^{\circ}$ 56, de 20/12/2007. São Paulo: Escala, 2008.
BRASIL. Presidência da República. Casa Civil. Subchefia para Assuntos Jurídicos. Lei n. 8.080, de 19 de setembro de 1990. Dispõe sobre as condições para a promoção, proteção e recuperação da saúde, a organização e o funcionamento dos serviços correspondentes e dá outras providências. Brasília, DF: Presidência da República, 1990. Disponível em: http:// www.planalto.gov.br/ccivil_03/leis/18080.htm. Acesso em 6 dez. 2017.

BRASIL. Portaria n. 2.728 de 11 de novembro de 2009. Dispõe sobre a Rede Nacional de Atenção Integral à Saúde do Trabalhador (RENAST) e dá outras providências. Brasília, DF: Ministério da Saúde, 2009. Disponível em: http://bvsms.saude. gov.br/bvs/saudelegis/gm/2009/prt2728_11_11_2009.html. Acesso em: 6 dez. 2017.

BRASIL. Portaria n. 1.823 de 23 de agosto de 2012. Institui a Política Nacional da Saúde do Trabalhador e da Trabalhadora. Brasília, DF: Ministério da Saúde, 2012. Disponível em: $\quad$ http://bvsms.saude.gov.br/bvs/saudelegis/gm/2012/ prt1823_23_08_2012.html. Acesso em: 6 dez. 2017.

BRITO, J. A. Ergologia como perspectiva de análise: a Saúde do Trabalhador e o trabalho em saúde. In: MINAYOGOMES, C.; MACHADO, J. M.; PENA, P. G. (Org.). Saúde do trabalhador na sociedade brasileira contemporânea. Rio de Janeiro: Fiocruz, 2011. p. 479-494.

BRITO, J. A. Documento técnico contendo a caracterização geral dos produtos gerados no âmbito dos Cursos de Especialização em Saúde do Trabalhador, oferecidos pela ENSP/FIOCRUZ. Rio de Janeiro: Escola Nacional de Saúde Pública-Fundação Oswaldo Cruz; Coordenação Geral de Saúde do Trabalhador (CGST)-MS/OPAS, 2015.

BRITO, J. A; ATHAYDE, M. Trabalho, educação e saúde: o ponto de vista enigmático da atividade. Educação, Saúde e Trabalho, v. 1, n. 2, p. 63-89, 2003.

BRITO, J. A.; ATHAYDE, M.; NEVES, M. Y. (Org.). Programa de formação em saúde, gênero e trabalho nas escolas: Caderno de método e procedimentos. João Pessoa: UFPB, 2003a.

BRITO, J. A.; ATHAYDE, M.; NEVES, M. Y. (Org.). Programa de formação em saúde, gênero e trabalho nas escolas: Caderno de textos. João Pessoa: UFPB, 2003b.

CANGUILHEM, G. O normal e o patológico. 5. ed. rev. e aum. Rio de Janeiro: Forense Universitária, 2000.

CENTRO DE REFERÊNCIA TÉCNICA EM PSICOLOGIA E POLÍTICAS PÚBLICAS. Saúde do trabalhador no âmbito da saúde pública: referências para a atuação do psicólogo. Brasília, DF : Conselho Federal de Psicologia, 2008.

CLOT, Y. Le problème des catachrèses en psychologie du travail: un cadre d'analyse. Le Travail Humain, v. 60, n. 2, p. 113-129, 1997.

CLOT, Y. Le travail à coeur: pour en finir avec les risques psichosociaux. Paris: La Découverte, 2010.

CLOT, Y. Le métier comme opérateur de santé. Bulletin de Psychologie, n. 511, p. 31-38, 2011.

CLOT, Y.; LHUILIER, D. (Dir.). Agir en clinique du travail. Paris: Érès, 2010.

CONSELHO FEDERAL DE PSICOLOGIA/CFP. Psicologia crítica do trabalho na sociedade contemporânea. Brasília, DF: Conselho Federal de Psicologia, 2010. 
DEJOURS, C. Note de travail sur a notion de souffrance. In: (Dir.) Plaisir et souffrance dans le travail. Séminaire interdisciplinaire de psychopatologie du travail. Orsay: AOCIP, 1988. p. 115-124. v. 1 .

DEJOURS, C. Repressão e subversão em psicossomática: pesquisas psicanalíticas sobre o corpo. Rio de Janeiro: J. Zahar, 1991.

DEJOURS, C. Subjetividade, trabalho e ação. Produção, v. 14, n. 3, p. 27-34, 2004.

DEJOURS, C. Trabalho vivo. Brasília: Paralelo 15, 2012. v. 2.

DURRIVE, L. Formação, trabalho, juventude: uma abordagem ergológica. Pro-Posições, v. 13, n. 3(39), p. 19-30, sept./dez. 2002.

DURRIVE, L. O formador ergológico ou "Ergoformador": uma introdução à ergoformação. In: SCHWARTZ, Y.; DURRIVE, L. (Org.). Trabalho \& Ergologia: conversas sobre a atividade humana. 2. ed. ampliada. Niterói: EdUFF, 2010a. p. 295-307.

DURRIVE, L. Pistas para o ergoformador animar os encontros sobre o trabalho. In: SCHWARTZ, Y.; DURRIVE, L. (Org.). Trabalho \& Ergologia: conversas sobre a atividade humana. 2. ed. ampliada. Niterói: EdUFF, 2010b. p. 309-318.

FREIRE, P. Pedagogia do Oprimido. 29. ed. São Paulo: Paz e Terra, 2000.

GUÉRIN, F. et al. Compreender o trabalho para transformá-lo: a prática da ergonomia. São Paulo: Edgard Blücher, 2001.

GOMES, G. C. Apresentação. Em extensão, v. 13, n. 2, p. 5-6, 2014.

JOBERT, G. Dire, penser, faire. À propos de trois métaphores agissantes en formation des adultes. Éducation Permanente, $\mathrm{n}$. 143, p. 7-28, 2000.

LACOMBLEZ, M. Analyse du travail et élaboration des programmes de formation professionnelle. Relations Industrielles/Industrial Relations, v. 56, n. 3, p. 543- 578, 2001.

LACOMBLEZ, M. et al. Marianne Lacomblez e a construção de uma Psicologia da Atividade de Trabalho. Cadernos de Psicologia Social do Trabalho, v. 19, n. 1, p. 121-133, 2016.

LIMA, M. E. Saúde Mental e Trabalho: limites, desafios, obstáculos e perspectivas. Cadernos de Psicologia Social do Trabalho (USP), São Paulo, v. 16, p. 91-98, 2013.

MASSON, L. P.; BRITO, J.; ATHAYDE, M. Dimensão relacional da atividade de cuidado e condições de trabalho de auxiliares de enfermagem em uma Unidade Neonatal. Physis, Revista de Saúde coletiva, v. 21, p. 879-898, 2011. Cross ${ }^{\text {Ref }}$

MINAYO-GOMES, C.; MACHADO, J. M. H.; PENA, P. G. L. (Org.). Saúde do trabalhador na sociedade brasileira contemporânea. Rio de Janeiro: Fiocruz, 2011.

MOLINIER, P. O trabalho e a psique: uma introdução à psicopatologia do trabalho. Brasília: Paralelo 15, 2013.

NEVES, M. Y.; BRITO, J.; ATHAYDE, M. Mobilização das professoras por saúde. In: GLINA, D. M. R.; ROCHA, L. E. Saúde mental no trabalho: da teoria à prática. São Paulo: Roca, 2010. p. 248-270.

PAPARELLI, R.; SATO, L.; OLIVEIRA, F. A Saúde Mental relacionada ao trabalho e os desafios aos profissionais de saúde. Revista Brasileira de Saúde Ocupacional, São Paulo, v. 36, n. 123, p. 118-127, 2011.

PASTRÉ, P. Didactique Professionnelle et développement. Psychologie Française, v. 42, n. 1, p. 89-100, 1997.
PASTRÉ, P.; MAYEN, P.; VERGNAUD, G. La Didactique Professionelle. Revue française de pédagogie, n. 154, p. 145198, 2006.

POLANYI, K. La grande transformation: aux origines politiques et économiques de notre temps. Paris: Gallimard, 1983.

RAMMINGER, T.; ATHAYDE, M.; BRITO, J. Ampliando o diálogo entre trabalhadores e profissionais de pesquisa: alguns métodos de pesquisa-intervenção para o campo da Saúde do Trabalhador. Ciência e Saúde Coletiva, Rio de Janeiro, v. 18, p. 3191-3202, 2013.

SANTOS, M.; LACOMBLEZ, M. Discutir o trabalho, fazer sabendo: Projeto de Formação Profissional de Adultos. Cadernos de Consulta Psicológica, n. 17-18, p. 305-311, 2001/2002. Disponível em: https://repositorio-aberto.up.pt/ bitstream/10216/14782/2/81852.pdf. Acesso em: 12 jun. 2013.

SAVOYANT, A. Une approche cognitive de l' alternance. CEREQ bref, n. 118, p. 1-4, 1996.

SCHWARTZ, Y. Le paradigme ergologique ou un métier de Philosophe. Toulouse: Octarès, 2000.

SCHWARTZ, Y. Disciplina Epistêmica, Disciplina Ergológica - Paideia e Politeia. Pro-posições. São Paulo, v. 13, n. 37, p. 126-149, 2002.

SCHWARTZ, Y. Ergonomia, filosofia e exterritorialidade. In: DANIELlOU, F. (Coord.). A ergonomia em busca de seus princípios: debates epistemológicos. São Paulo: Edgard Blücher, 2004. p. 141-180.

SCHWARTZ, Y. ; DURRIVE, L. (Org.). Trabalho \& Ergologia: conversas sobre a atividade humana. 2. ed. ampliada. Niterói: EdUFF, 2010.

SELIGMANN-SILVA, E. Trabalho e desgaste mental: o direito de ser dono de si mesmo. São Paulo: Cortez, 2011.

SILVA, E. F. et al. A promoção da saúde a partir das situações de trabalho. Interface. Comunicação, Saúde e Educação, v. 13, p. 20-30, 2009.

SOUZA, W. F. Transtornos mentais e comportamentais relacionados ao trabalho: o que a Psicologia tem a dizer e a contribuir para a saúde de quem trabalha? Fractal: Revista de Psicologia, Niterói, v. 25, n. 1, p. 99-108, 2013. Cross ${ }^{\mathrm{Ref}}$

SOUZA, W. F.; RODRIGUES, A. L.; SANTOS, T. A. Encontros com a atividade: a extensão do diálogo sobre trabalho, gestão e saúde mental. Em extensão, v. 13, n. 2, p. 49-60, 2014.

SOUZA, W. F.; CHRISTO, C. Trabalho, vida e gestão: vias para um ergogerenciamento. In: TAVEIRA, I. M. R.; LIMONGIFRANÇA, A. C.; FERREIRA, M. C. (Org.). Qualidade de vida no trabalho: estudos e metodologias brasileiras. Curitiba: CRV, 2015. p. 359-375.

SUPRANI, B.; ATHAYDE, V.; ATHAYDE, M. Vida, saúde mental e trabalho: algumas pistas para compreendertransformar. Advir (ASDUERJ), Rio de Janeiro, v. 33, p. 86-98, 2015.

TEIGER, C.; LACOMBLEZ, M. (Org.) (Se) Former pour transformer le travail: dynamiques des constructions d'une analyse critique du travail. Quebec: PUL, 2013.

THÉRY, L. Introduction. In: (Dir.) Le travail intenable: résister collectivement à l'intensification du travail. Paris: $\mathrm{La}$ Découverte, 2006. p. 5-16.

Recebido em: 2 de junho de 2017 Aceito em: 17 de janeiro de 2018 